
\title{
How is depression related
to education?
}

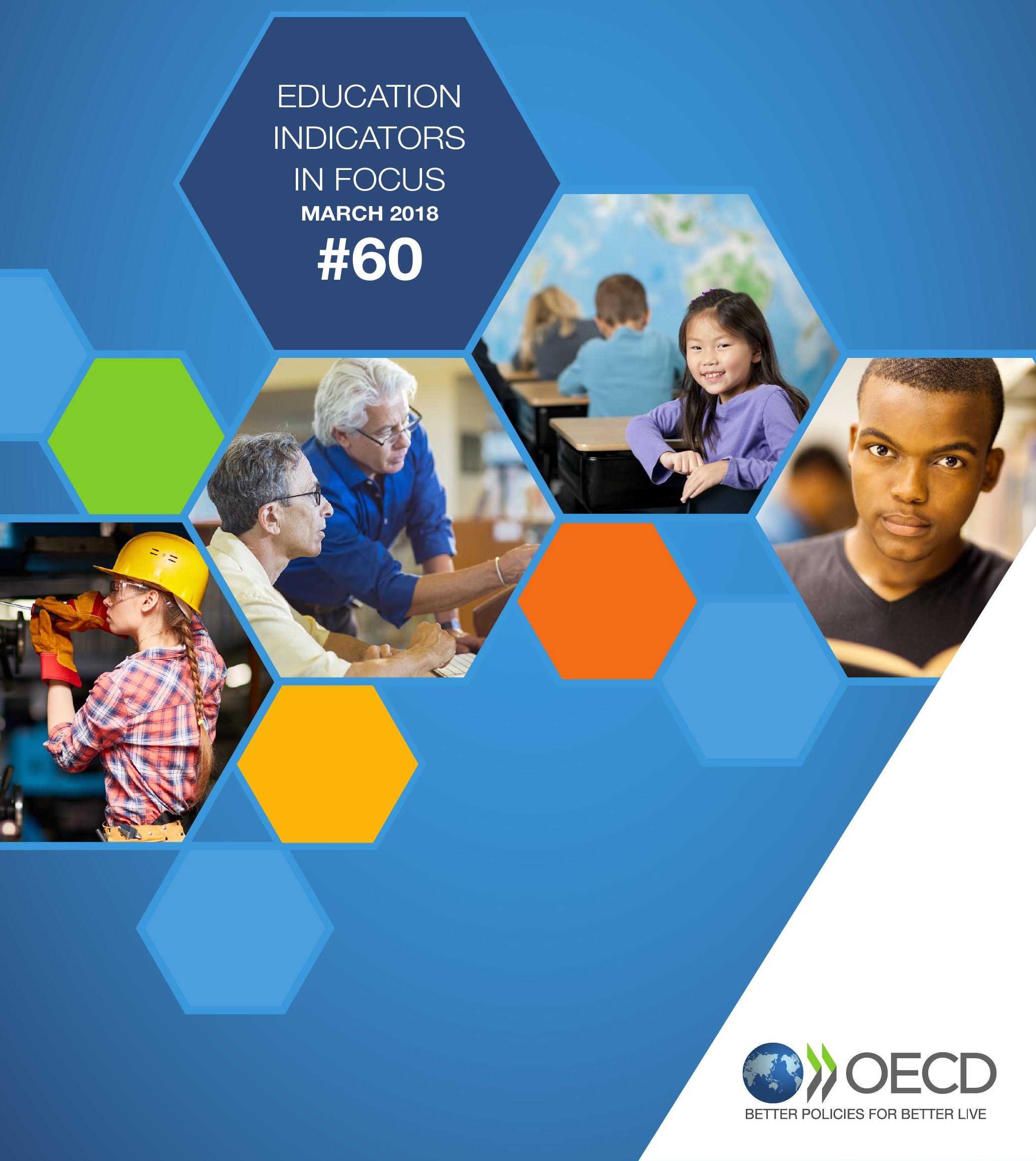




\section{How is depression related to education?}

- People with higher educational attainment are less likely to report depression than those with lower education attainment.

- Women are more likely to report having depression than men at all levels of educational attainment, but their share decreases more steeply as their educational attainment increases than it does for men.

- Those who are employed report lower levels of depression than those who are not, but regardless of employment status, higher education is associated with a lower prevalence of self-reported depression.

Mental health is an important social outcome, and education and depression are clearly correlated. Higher educational attainment is associated with a lower prevalence of depression but depression itself may be a reason for lower educational attainment. People with lower cognitive skills tend to leave school earlier and may present some of the personal characteristics associated with depression. In any case, education systems have a role to play in tackling depression, an illness estimated to be the leading cause of disability and affecting over 300 million people worldwide (WHO, 2017 ${ }^{[1]}$ ).

Most mental illness has its onset in childhood or adolescence and mental illness is at least as prevalent among young people as among adults, as the OECD report, Fit Mind, Fit Job recorded (OECD, $2015^{[2]}$. Bullies and victims of bullying have a greater likelihood of depressive symptoms (Haynie et al., 2001 ${ }^{[3]}$ ). Chronic stress related to the pressure to succeed in school, family instability, poverty, sleep deprivation, low self-esteem or self-confidence, and poor social relations with peers, parents and teachers are other factors positively associated with depression among students (Choi, 2017 $7^{[4]}$; OECD, 2015 $5^{[5]}$ ). Education systems can help to identify individuals who are susceptible to developing a mental illness and give them appropriate support (OECD, 2015 $5^{[2]}$.

\section{Definition, source and methodology}

The World Health Organization defines depression as an illness characterised by persistent sadness and a loss of interest in activities that you normally enjoy, accompanied by an inability to carry out daily activities, for at least two weeks. In addition, people with depression normally have several of the following: a loss of energy; a change in appetite; sleeping more or less; anxiety; reduced concentration; indecisiveness; restlessness; feelings of worthlessness, guilt, or hopelessness; and thoughts of self-harm or suicide (WHO, 2017 $\left.{ }_{[6]}\right)$.

As explained in Education at a Glance 2017 (OECD, 2017 $)$, this analysis is based on data from the European Health Interview Survey (EHIS) for the 22 OECD/EU countries and for Iceland, Norway and Turkey. National surveys were used for Australia (National Health Survey), Canada (Canadian Community Health Survey), Israel (Social Survey) and Switzerland (Swiss Health Survey).

All these surveys involve self-reported data but the questions asked vary across surveys with some questions asking more specifically about medically diagnosed or medically treated depression (see Education at a Glance 2017 for more information). For EHIS, data on depression are drawn from a sub-module on chronic diseases or conditions and refer to those who responded "yes" to the following question: "During the past 12 months, have you had any of the following diseases or conditions? Yes/No" (where one of the items is depression).

This means that the analysis is not looking at rates of clinical depression but at self-diagnosed depression among 25-64 year-olds in the 12 months prior to the survey. People who live in countries with greater awareness of and easier access to mental health services are likely to report higher rates of depression. Where the information was drawn from national surveys, the questions were different, so those results are not directly compared in the text or figures.

Reference period: data for EHIS refer to 2014; data for Australia refer to the financial year 2014/15; data for Canada refer to 2012; data for Israel refer to 2016; data for Switzerland refer to 2012. 


\section{Educational attainment and self-reported depression}

Although causal interpretation is not possible, EHIS data shows that rates of self-reported depression tend to fall with higher educational attainment. The same general trends are observed in national surveys in Australia, Canada, Israel and Switzerland where adults with a tertiary degree report lower depression than adults without one (Figure 1).

Figure 1 shows that the same association persists across all countries with data: the higher the educational attainment, the lower the self-reported depression. The only exceptions are Canada, Estonia, Latvia and Sweden where, although the tendency is similar, the difference between each attainment level is not statistically significant (OECD, 2017 ${ }_{[7]}$ ).

FIGURE 1 / Percentage of adults who report having depression, by educational attainment (2014)

European Health Interview Survey and national surveys, 25-64 year-olds

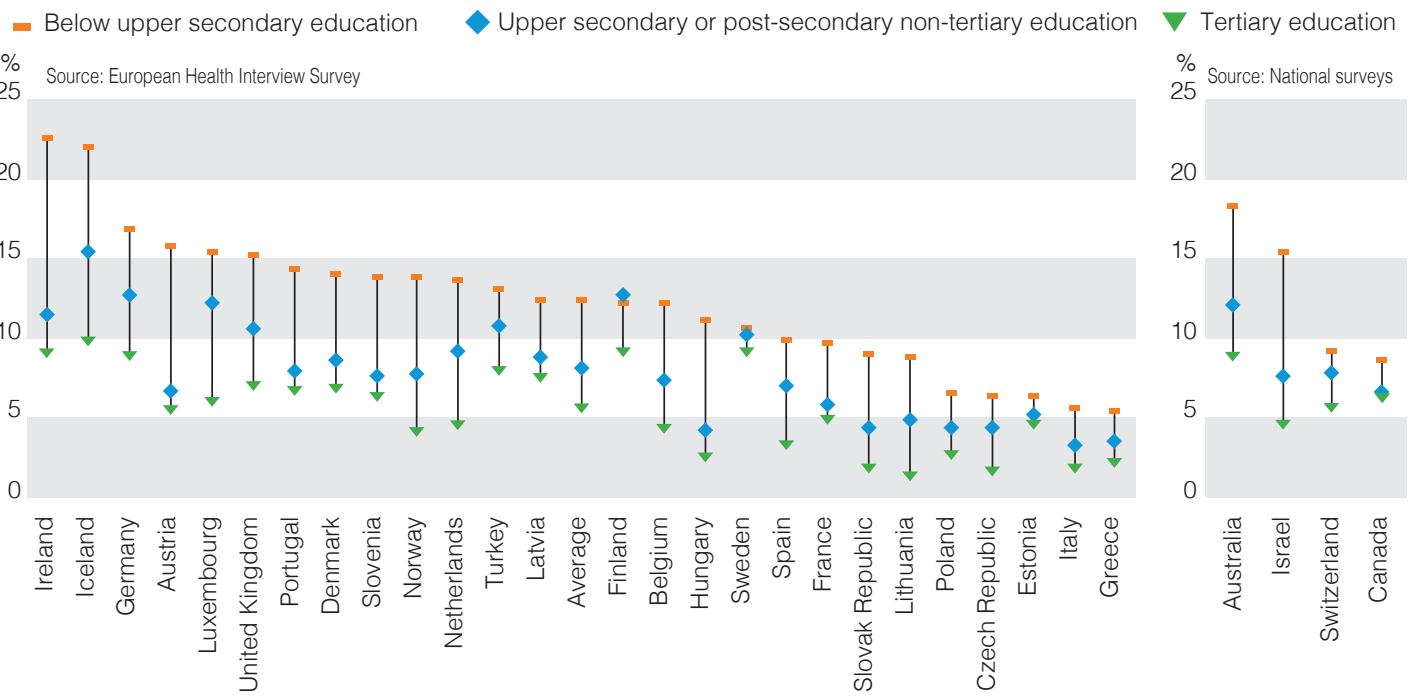

Note: As the questions asked in the different surveys vary, survey results are not directly compared in the analysis.

Source: OECD (2017), Education at a Glance 2017: OECD Indicators, http://dx.doi.org/10.1787/eag-2017-en.

Among the OECD countries that participated in EHIS, Iceland has the highest share of adults who reported having depression in the 12 months prior to the survey (14\%). But differences by educational attainment are large. Along with Ireland, Iceland is the only country where the share of self-reported depression among adults without upper secondary education is above $20 \%$. This share drops to about 15\% among adults who completed upper secondary or post-secondary non-tertiary education and to 10\% among tertiary-educated adults (Figure 1). These high shares are in line with the results from Health at a Glance 2015 showing that Iceland was the largest consumer of antidepressants across OECD countries with 118 out of every 1000 adults taking these drugs on a daily basis (OECD, 2015[8]).

In contrast, self-reported depression is generally low in Greece and Italy. A study by Munizza et al. $\left(2013^{[9]}\right)$ showed that the low share in Italy might be related to public beliefs and attitudes towards reporting depression. The results showed that three-quarters of Italians believe that people suffering from depression should avoid talking about their problem.

The completion of upper secondary and tertiary education has varying associations with selfreported depression across countries. On average, the greatest difference across education levels is between adults with and without upper secondary education. This is not the case in Finland and Luxembourg where the largest difference is between tertiary-educated adults and adults with upper secondary or post-secondary non-tertiary education (Figure 1).

\section{Gender, self-reported depression and educational attainment}

Women are more likely to report having depression than men. On average across the OECD countries participating in EHIS, 10\% of women report experiencing depression in the 12 months prior to the 
survey compared to $6 \%$ of men. The higher prevalence of self-reported depression among women holds across all countries with data, but the differences are particularly large in Portugal and Turkey where the gender gap is around 10 percentage points. Similar trends are observed in national surveys in Australia, Canada, Israel and Switzerland where the gender gap varies between 1 and 4 percentage points (OECD, 2017[7]).

However, while self-reported depression is generally higher among women than men, its prevalence decreases more steeply for women as they a cquire further qualifications. Ross and Mirowsky (2006 $\left.{ }^{[10]}\right)$ also underline that, unlike the gender earnings gap, which is greater among highly educated adults, women in this group tend to be less depressed than less-educated women.

In most countries, the difference in self-reported depression between low-educated and highly educated adults is greater among women than among men (Figure 2). On average across the OECD countries that participated in EHIS the share of low-educated men who report having depression is 5 percentage points higher than the share among tertiary-educated men; for women the difference is almost twice as large (9 percentage points).

Iceland, Ireland and Lithuania are the only three countries where the gap in self-reported depression between low-educated and highly educated women is at least 15 percentage points. Of these three countries, the gender difference is particularly important in Lithuania. This is related to the particularly high share of self-reported depression among low-educated women (17\%) while the share among highly educated women is low (2\%) (OECD, 2017[7]). Fortunately, only 6\% of women are low-educated in Lithuania, much lower than the OECD average of 23\% (OECD, 2017[11]).

The difference in self-reported depression by educational attainment in Sweden shows a different picture when further disaggregating by gender. While Figure 1 shows close to no difference in the share of self-reported depression by educational attainment, Figure 2 highlights a striking difference between men and women (Figures 1 and 2).

\section{FIGURE 2 / Difference in self-reported depression between low-educated and highly educated adults, by gender (2014)}

European Health Interview Survey and national surveys, 25-64 year-olds

\section{Percentage points}

Women Men
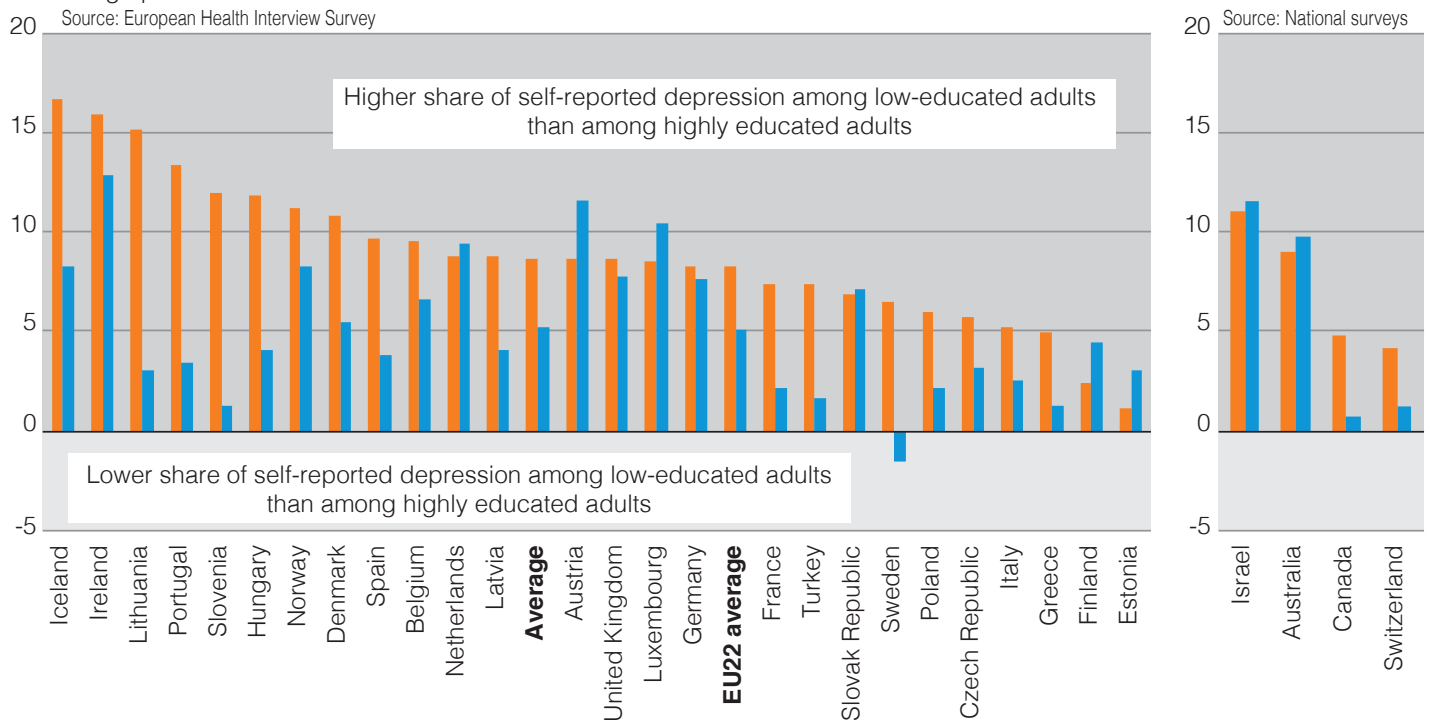

Note: As the questions asked in the different surveys vary, survey results are not directly compared in the analysis. Low-educated adults refers to adults without upper secondary education and highly educated adults refers to tertiary-educated adults.

Source: OECD (2017), Education at a Glance 2017: OECD Indicators, http://dx.doi.org/10.1787/eag-2017-en. 


\section{Labour market status, self-reported depression and educational attainment}

Although the prevalence of mental illness has not increased, greater awareness leads to an increase in the number of diagnosed cases and to mentally ill people suffering greater labour market exclusion (OECD, 2012 ${ }^{[12]}$ ). Those who have a mental illness have more difficulty finding a job and when they do find one, they are more likely to struggle to deliver what is expected of them and often show comparatively low productivity (OECD, 2012 ${ }^{[12]}$ ). However, individuals with mental illness who find work often show improvement in their condition, as their labour-force status increases their selfesteem and sense of worth in society. It is therefore crucial that education systems ensure a smooth school-to-work transition for all, and especially for those who perform poorly at school as they are the ones who are most likely to suffer from mental illness (OECD, 2015 ${ }^{[2]}$ ).

Figure 3 shows that being in employment is associated with a lower prevalence of self-reported depression compared with the whole population (employed, unemployed and inactive). However, the difference in self-reported depression between these two groups is much larger for low-educated adults than for those who completed at least upper secondary education.

Among low-educated adults, 7\% of those in employment report they had depression in the 12 months prior to the survey. When the unemployed and the inactive population are added to this group, the prevalence of self-reported depression rises by 5 percentage points. Among adults with upper secondary or post-secondary non-tertiary education the rise is only 2 percentage points, and only 1 percentage point among tertiary-educated adults. This means that, regardless of labour-force status, completing tertiary education is associated with a lower prevalence of depression (Figure 3).

FIGURE 3 / Difference in self-reported depression between all 25-64 year-olds and employed 25-64 year-olds, by educational attainment (2014)

European Health Interview Survey and national surveys, 25-64 year-olds

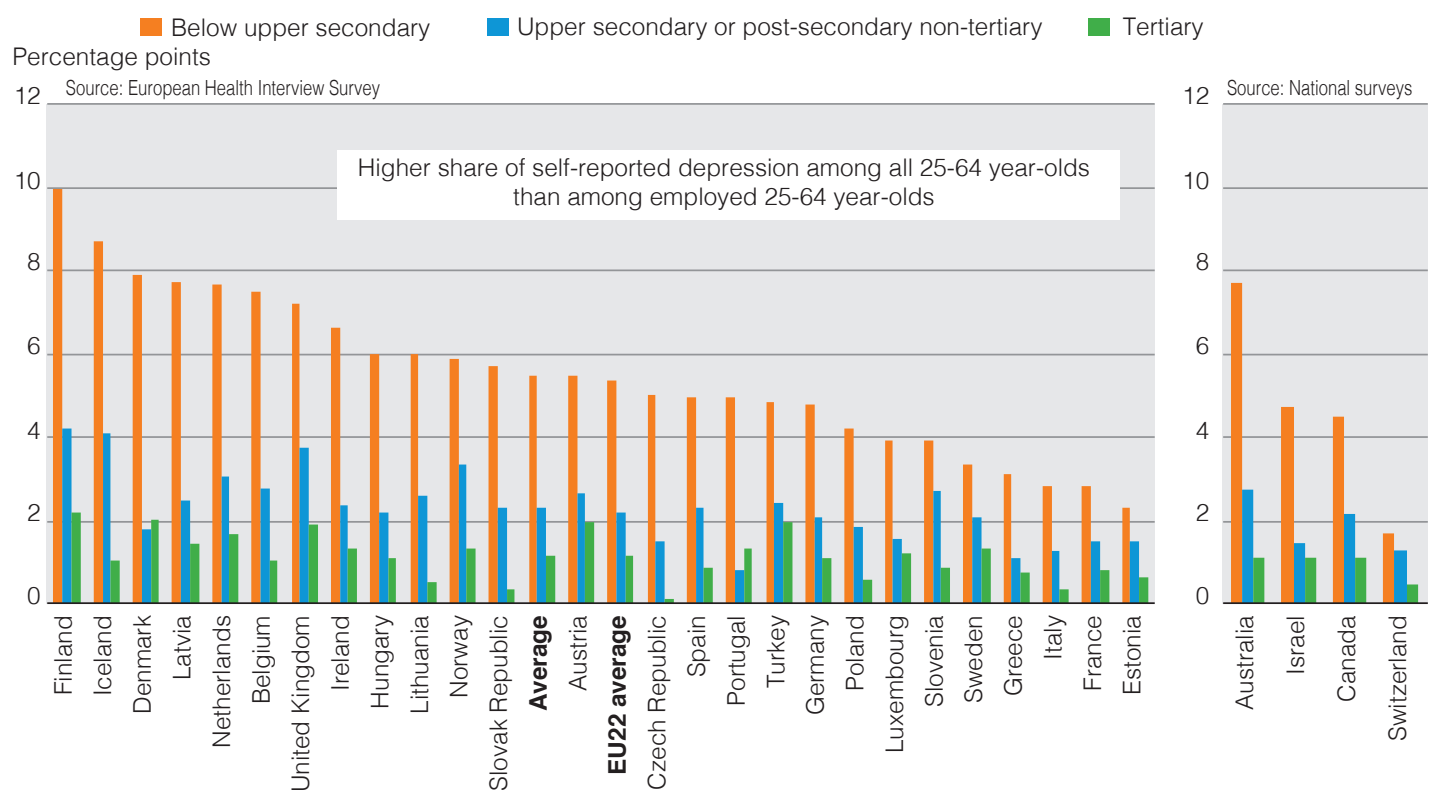

Note: As the questions asked in the different surveys vary, survey results are not directly compared in the analysis.

Source: OECD (2017), Education at a Glance 2017: OECD Indicators, http://dx.doi.org/10.1787/eag-2017-en.

In Finland, 2\% of low-educated employed adults reported having depression, but when unemployed and inactive adults are included, the share rises to $12 \%$. This 10 percentage-point difference between the two groups is the largest among OECD countries with data. In contrast, Estonia has the lowest difference in self-reported depression for these two groups among the OECD countries that participated in EHIS. This shows that in Estonia self-reported depression is generally low across the different educational attainment levels, but also across genders and different labour-force statuses. 


\section{The bottom line}

People with higher levels of education report less prevalence of depression in all OECD countries with data. A greater share of women than men report suffering from depression, but the share decreases more steeply for women than for men as educational attainment increases. Employment is associated with a lower share of self-reported depression, especially among low-educated adults. Given that mental illness has its onset in childhood or adolescence, these findings highlight the important role education systems play in ensuring students complete their education and successfully transition into the workplace.

\section{FOR MORE INFORMATION:}

[4] Choi, A. (2017), "Emotional well-being of children and adolescents: Recent trends and relevant factors", OECD, Paris, http://www.oecd.org/officialdocuments/publicdisplaydocumentpdf/?cote=EDU/CERI/CD/ RD\%282017\%298\&docLanguage=En (accessed on 06 March 2018).

[3] Haynie, D. et al. (2001), "Bullies, victims, and bully/victims", The Journal of Early Adolescence, Vol. 21/1, pp. 29-49, http://dx.doi.org/10.1177/0272431601021001002.

[9] Munizza, C. et al. (2013), "Public beliefs and attitudes towards depression in Italy: A national survey", PLOS ONE, Vol. 8/5, p. e63806, http://dx.doi.org/10.1371/journal.pone.0063806.

[12] OECD (2012), Sick on the Job?: Myths and Realities about Mental Health and Work, Mental Health and Work, OECD Publishing, Paris, http://dx.doi.org/10.1787/9789264124523-en.

[2] OECD (2015), Fit Mind, Fit Job: From Evidence to Practice in Mental Health and Work, Mental Health and Work, OECD Publishing, Paris, http://dx.doi.org/10.1787/9789264228283-en.

[8] OECD (2015), Health at a Glance 2015: OECD Indicators, OECD Publishing, Paris, http://dx.doi.org/10.1787/ health_glance-2015-en.

[5] OECD (2015), Skills for Social Progress: The Power of Social and Emotional Skills, OECD Skills Studies, OECD Publishing, Paris, http://dx.doi.org/10.1787/9789264226159-en.

[7] OECD (2017), Education at a Glance 2017: OECD Indicators, OECD Publishing, Paris, http://dx.doi. org/10.1787/eag-2017-en

[11] OECD (2017), "Educational attainment and labour-force status", Education at a Glance Database, OECD Stat, http://stats.oecd.org/Index.aspx?DataSetCode=EAG_NEAC (accessed on 06 February 2018).

[10] Ross, C. and J. Mirowsky (2006), "Sex differences in the effect of education on depression: Resource multiplication or resource substitution?”, Social Science \& Medicine, Vol. 63/5, pp. 1400-1413, http://dx.doi. org/10.1016/J.SOCSCIMED.2006.03.013.

[1] WHO (2017), Depression fact sheet, World Health Organization, http://www.who.int/mediacentre/ factsheets/fs369/en/ (accessed on 06 March 2018).

[6] WHO (2017), Depression: What you should know, World Health Organization, http://www.who.int/campaigns/ world-health-day/2017/handouts-depression/what-you-should-know/en/ (accessed on 08 March 2018).

VISIT

www.oecd.org/education/education-at-a-glance-19991487.htm

Education Indicators in Focus (previous issues)

PISA in Focus

Teaching in Focus

NEXT TOPIC The global talent pool of students

CONTACT:

Simon Normandeau (Simon.Normandeau@oecd.org)

Photo credit: @ Christopher Futcher / iStock; @ Marc Romanelli / Gettyimages; @ michaeljung / Shutterstock; @ Pressmaster / Shutterstock This work is published under the responsibility of the Secretary-General of the OECD. The opinions expressed and arguments employed herein do not necessarily reflect the official views of OECD member countries.

This document, as well as any data and any map included herein, are without prejudice to the status of or sovereignty over any territory, to the delimitation of international frontiers and boundaries and to the name of any territory, city or area.

The statistical data for Israel are supplied by and are under the responsibility of the relevant Israeli authorities. The use of such data by the OECD is without prejudice to the status of the Golan Heights, East Jerusalem and Israeli settlements in the West Bank under the terms of international law. 